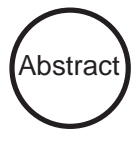

This article investigates how a corporate tax holiday affects a firm's incentive to invest when irreversibility interacts with uncertainty. The firm has a monopoly right to exercise a single, discrete, infinitely lived project. After exercising the project, at each instant, the firm receives one unit of output while incurring a fixed amount of operating and maintenance costs. The firm can temporarily and costlessly both shut down and resume its operation. A more generous tax incentive (i.e., a longer tax holiday or a lower corporate tax rate) will discourage a firm's incentive to invest if the firm's value from delaying investment is increased by more than its value of investing immediately. This is more likely to happen if capital assets either are shortlived or yield a return that is very volatile.

\title{
IRREVERSIBLE INVESTMENT DECISIONS UNDER UNCERTAINTY WITH TAX HOLIDAYS
}

$J Y H-B A N G J O U$

National Taiwan University

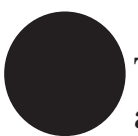

The literature on the effect of a corporate tax holiday typically assumes that investment both yields a nonstochastic return and is costlessly reversible (e.g., Mintz 1990; Mintz and Tsiopoulos 1994). ${ }^{1}$ The following asset characteristics emphasized by "real options" literature (Dixit and Pindyck 1994, 3) are thus ignored: First, the investment costs are usually sunk because of asset specificity, the "lemons" problem, or governmental interventions. Second, the future rewards from the investment are usually stochastic. Finally, there is some leeway about the timing of investment. By employing the real options approach, this article shows that a more generous tax incentive, either a lower corporate income tax rate or a longer tax holiday, may fail to stimulate investment.

AUTHOR'S NOTE: I thank Professor J. Ronnie Davis (the editor) and one anonymous referee for helpful comments.

\$ PUBLIC FINANCE REVIEW, Vol. 28 No. 1, January $200066-81$

(c) 2000 Sage Publications, Inc.

66 
This article adds tax holidays into the model of discrete investment decisions commonly used in real options literature (e.g., Brennan and Schwartz 1985; McDonald and Siegel 1985). A risk-neutral firm, owned by risk-averse investors, is assumed to have a privileged opportunity to exercise a single, discrete, infinitely lived project. To exercise the project, the firm should purchase and install capital that has no resale value and is depreciating at a constant rate. Once exercising the project, at each instant, the firm is able to produce one unit of output whose price is stochastic over time while incurring both operating and maintenance costs. The firm can temporarily and costlessly shut down its operation if the output price is below these operation and maintenance costs and costlessly resume later otherwise. The firm also receives a tax holiday immediately after exercising the project. ${ }^{2}$

The firm should compare the benefit of investing immediately with that from delaying investment when deciding whether to invest. A more generous tax policy (i.e., a longer tax holiday or a lower corporate tax rate) is then found to exhibit an ambiguous effect on the firm's incentive to invest. This is because the benefit of investing immediately and the benefit from delaying investment will then be both raised. If the latter is raised by more than is the former, then the firm's incentive to invest will be reduced. This is more likely to happen if capital assets either are short-lived or yield a return that is very volatile.

This article is related to the studies on the risk-sharing effects of taxation in an uncertain world. Domar and Musgrave (1944) suggest that the government shifts part of the risk onto itself when taxing income with full-loss offsets. Stiglitz (1969) allows the taxation of risky income either with or without loss offset. Mintz (1981) suggests that the assumption about production technology determines whether a corporate tax with full-loss offset can encourage risky investment. Gordon (1985) examines the taxation of risky income with full-loss offsets in a general equilibrium framework. Majd and Myers (1985, 1986) examine the effects of loss carry-forwards, and both Auerbach (1986) and Mayer (1986) examine the asymmetric effects of tax losses. This article considers both cases of full- and no-loss offsets and departs from these articles by allowing the interaction between risk sharing and the time-contingent tax holiday policy. 
This article is also related to those articles that apply "real options" to examine tax incentives other than tax holidays. Hassett and Metcalf (1992) suggest that uncertain investment tax credits may encourage investment. MacKie-Mason (1990) examines the stimulus effect of depletion allowances and yields results similar to those of this article: A more generous tax incentive, either a lower corporate tax rate or a higher rate of depletion allowance, may fail to encourage investment.

The remainder of this article is as follows. The next section presents my model, followed by a section that provides numerical simulations to demonstrate computation feasibility of this model. The last section concludes and suggests extensions for future research.

\section{THE MODEL}

I add tax holidays into the model on discrete investment decisions commonly used in real options literature (e.g., Brennan and Schwartz 1985; McDonald and Siegel 1985). A risk-neutral firm, owned by risk-averse investors, is assumed to maximize the expected discounted profits. The firm has a privileged right to exercise a single, discrete, infinitely lived project. To exercise this project, the firm should purchase and install capital at the cost $k$. Installed capital both has no resale value and is depreciating exponentially at a constant rate $\delta_{1}$. Once exercising this project, at each instant $t$, the firm has a capacity to produce one unit flow of output with a stochastic price $P(t)$ while incurring the cost of $w+\delta_{1} k ; w$ is the fixed operating costs, and $\delta_{1} k$ is the maintenance costs required to maintain one unit flow of output at each instant. I also assume that the firm can temporarily and costlessly suspend its operation if $P(t)$ is below $w+\delta_{1} k$ and can costlessly resume later otherwise.

The output price $P(t)$ follows a geometric Brownian motion:

$$
\frac{d P(t)}{P(t)} \mu_{p} d t+\sigma d Z(t)
$$

where $\mu_{p}$ is the expected growth rate of $P(t), \sigma(>0)$ is the instantaneous volatility of that growth rate, and $d Z(t)$ is the increment of a standard Wiener process. Equation (1) indicates that the current output 
price is known to the firm, and the future output price is log-normally distributed with a variance that grows over time.

Suppose that the firm's output is not a hedged asset but can be spanned by existing assets. Denote the price of an asset or a portfolio of assets perfectly correlated with $P(t)$ as $X(t)$, which evolves as

$$
\frac{d X(t)}{X(t)} \mu_{x} d t+\sigma d Z(t)
$$

and by the capital asset pricing model (CAPM), $\mu_{x}=r+\Phi \rho_{p m} \sigma$, where $r$ is the risk-less rate, $\Phi$ is the market price of risk, and $\rho_{p m}$ is the correlation coefficient between $d P(t) / P(t)$ and the rate of return on the market portfolio. Denote $\delta_{0}$ as the shortfall of returns, which is the difference between $\mu_{x}$ and $\mu_{p}$ - that is, $\delta_{0}=\mu_{x}-\mu_{p}$. Because $P(t)$ is expected to grow at a rate equal to $\mu_{P}$, the required return for holding the output is $\mu_{P}$, so that $\delta_{0}$ must accrue as some kind of dividend. This $\delta_{0}$ represents the opportunity cost to exercise the project rather than delay it, and thus its value should be positive; otherwise, no rational investors will exercise the project at all.

Once the firm exercises the project, it is granted with a corporate tax holiday of $T$ periods, during which it does not need to pay any corporate income tax. Suppose that the investment costs are free of taxation but the operating profits are taxed at a rate equal to $h$. Denote the firm's after-tax flow profit at time $t$ as $\pi(P(t))$. Its value depends on both whether the firm's loss can be offset and whether the economic rate of depreciation, $\delta_{1}$, is larger than the "allowed" depreciation rate for tax purposes, denoted by $\delta_{2}$. Suppose that both $i$ and $j$ are switching variables: $i=1$ if $P(t) \geq w+\delta_{1} k$, and $i=0$ otherwise, while $j=1$ if $t>T$, and $j=0$ otherwise. Three cases will then arise: (a) if $\delta_{1}>\delta_{2}$, then

$$
\pi(P(t))=\max \left[0, P(t)-w-\delta_{1} k\right]-h \cdot i \cdot j \cdot \max \left[0, P(t)-w-\delta_{2} k\right] ;
$$

(b) if $\delta_{2} \geq \delta_{1}$ with full-loss offsets, then

$$
\pi(P(t))=\max \left[0, P(t)-w-\delta_{1} k\right]-h \cdot i \cdot j \cdot\left(P(t)-w-\delta_{2} k\right) ;
$$

(c) if $\delta_{2} \geq \delta_{1}$ without any loss offsets, then

$$
\pi(P(t))=\max \left[0, P(t)-w-\delta_{1} k\right]-h \cdot j \cdot \max \left[0, P(t)-w-\delta_{2} k\right] .
$$


Equation (3) shows that if $\delta_{1}>\delta_{2}$, then the after-tax flow profit with full-loss offsets will be equal to that without any loss offsets; ${ }^{4}$ this is because the firm is able to temporarily and costlessly suspend its operation. As a result, once the firm operates, its operating profit, $P(t)-$ $w-\delta_{1} k$, will be nonnegative. The firm's taxable income, $P(t)-w-\delta_{2} k$, will then be also nonpositive because $\delta_{1}>\delta_{2}$. However, if $\delta_{2} \geq \delta_{1}$, then the firm's taxable income may be negative, and thus its after-tax profit with full-loss offsets, as shown by equation (3'), will be more valuable than that without any loss offsets, as shown by equation (3"). The "allowed" depreciation rate for tax purposes $\left(\delta_{2}\right)$ may be lower than its economic rate $\left(\delta_{1}\right)$ in the presence of technological changes. For ease of exposition, I abstract from this and focus on the case in which $\delta_{2} \geq$ $\delta_{1}$. Consequently, I use equations ( $\left.3^{\prime}\right)$ and ( $\left.3^{\prime \prime}\right)$ instead of equation (3) to derive the firm's investment value.

The firm's value, $V(P(t), T)$, is the pretax discounted present value of flow profits, $V_{1}(P(t))$, net of the discounted present value of corporate income taxes, $h V_{2}(P(t), T)$. Using equations ( $\left.3^{\prime}\right)$ and (3") yields

$$
\begin{aligned}
V(P(t), T) & =\int_{t}^{\infty} \int_{t}^{\infty} \pi(P(\tau)) f(P(\tau)) d P(\tau) \cdot e^{-\mu_{x}(\tau-t)} d \tau \\
& =\int_{t}^{\infty} C_{1}(P(t), \tau) d \tau-h \int_{t+T}^{\infty} C_{2}(P(t), \tau) d \tau \\
& =V_{1}(P(t))-h V_{2}(P(t), T),
\end{aligned}
$$

where $\mu_{x}$ is the firm's risk-adjusted discount rate, $f(P(\tau))$ is the density function for $P(\tau)$, and $C_{i}(P(t), \tau)(i=1$ or 2$)$ is the present value at time $t$ of a European call option on an "underpriced" asset, which gives its asset owner the right to buy a one-unit output at time $\tau$ at the cost of $w+\delta_{i} k$ while receiving the output price $P(\tau)$. Because $C_{i}(P(t), \tau)$ is analogous to a European call option on a dividend-paying stock, its pricing formula is given by the following (Merton 1973; McDonald and Siegel 1984):

$$
C_{i}(P(t), \tau)=P(t) e^{-\delta_{0}(\tau-t)} N\left(d_{1}\right)-\left(w+\delta_{i} k\right) e^{-r(\tau-t)} N\left(d_{2}\right),
$$

where 


$$
d_{1}=\frac{\left[\ln \frac{P(t)}{\left(w+\delta_{j} k\right)}+\left(r-\delta_{0}+\frac{\sigma^{2}}{2}\right)(\tau-t)\right]}{\sqrt{\sigma(\tau-t)}}, d_{2}=d_{1}-\sigma \sqrt{(\tau-t)} .
$$

$N(\bullet)$ is the standard normal cumulative distribution, and $j$ is a switching variable: $j=1$ if $i=1$ or if $i=2$ with full-loss offsets, and $j=2$ if $i=2$ without any loss offsets.

In the appendix, I use the contingent claims analysis to derive $V_{1}(P(t))$, the first term on the left-hand side of equation (4), ${ }^{5}$ which is

$$
\begin{gathered}
V_{1}(P(t))-b_{1} P(t)^{\beta_{1}} ; \\
b_{2} P(t)^{\beta_{2}}+\frac{P(t)}{\delta_{0}}-\frac{w+\delta_{1} k}{r} ; P(t) \geq w+\delta_{1} k, \\
b_{1}=\frac{\left(w+\delta_{1} k\right)^{1-\beta_{1}}}{\beta_{1}-\beta_{2}}\left(\frac{\beta_{2}}{r}-\frac{\beta_{2}-1}{\delta_{0}}\right), \\
b_{2}=\frac{\left(w+\delta_{1} k\right)^{1-\beta_{2}}}{\beta_{1}-\beta_{2}}\left(\frac{\beta_{1}}{r}-\frac{\beta_{1}-1}{\delta_{0}}\right),
\end{gathered}
$$

and $\beta_{1}$ and $\beta_{2}$ are the larger and smaller roots in equation (A9) in the appendix. I briefly examine the effects of some underlying parameters on $V(P(t), T)$ in equation (4), which will be used later. First, $V(P(t), T)$ is both decreasing with $h$ and increasing with $T$; this implies that a more generous tax incentive, either a lower corporate tax rate or a longer tax holiday, leads to a higher firm value. Second, when $\delta_{1}=\delta_{2}$, then $V(P(t), T)$ is both decreasing with $\delta_{1}$ and increasing with $\sigma$; this implies that if a firm is granted with tax holidays and its allowed depreciation rate for tax purposes is equal to its economic rate (i.e., $\delta_{1}=$ $\delta_{2}$ ), then the firm's value will be higher if capital assets either are long-lived $\left(\delta_{1}\right.$ is lower) or yield a return that is more volatile ( $\sigma$ is higher).

Now I examine the firm's investment decision. If the firm's option to invest is also completely irreversible, then its value of the option to invest, $F(P(t)$ ), will be given by the following (see the appendix): 


$$
F(P(t))=A P(t)^{\beta_{1}},
$$

where $A$ is a constant to be determined. The interaction of uncertainty and irreversibility suggests that the firm faces an impulsive control problem (Harrison, Sellke, and Taylor 1983). Consequently, the firm should exercise the project immediately as the output price reaches a critical value $P^{*}(t)$. At this critical level, two optimal conditions must be satisfied (Merton 1973). First,

$$
F(P *(t))=V_{1}\left(P^{*}(t)\right)-h V_{2}\left(P^{*}(t), T\right)-k
$$

Equation (8) indicates that upon investing, the firm's net gain from investing, the terms on the right-hand side, should be equal to its option value from delaying investment, the term on the left-hand side. Second,

$$
\frac{\partial F\left(P^{*}(t)\right)}{\partial P(t)}=\frac{\partial V_{1}\left(P^{*}(t)\right)}{\partial P(t)}-h \frac{\partial V_{2}\left(P^{*}(t), T\right)}{\partial P(t)} .
$$

Equation (9) indicates that at the point of investing, the marginal gain from investing should be equal to that from awaiting to prevent arbitrage opportunities. Note that I use the operating region (i.e., $P(t) \geq w+$ $\delta_{1} k$ ) when I plug $V_{1}(P(t))$ in equation (6) into equations (8) and (9) because a rational firm will not incur the investment cost only to keep the project idle. In addition, for $P^{*}(t)$ to be unique, it is also required that

$$
\frac{\partial^{2} F(P *(t))}{\partial P(t)^{2}}>\frac{\partial^{2} V_{1}(P *(t))}{\partial P(t)^{2}}-h \frac{\partial^{2} V_{2}(P *(t), T)}{\partial P(t)^{2}}
$$

Multiplying equation (9) by $P^{*}(t) / \Omega_{1}$ and then subtracting the result from equation (8) and using equations (4), (5), (6), and (7) yields

$$
\begin{aligned}
& {\left[V_{1}(P *(t))-\frac{\partial V_{1}(P *(t))}{\partial P(t)} \frac{P *(t)}{\beta_{1}}\right]} \\
& \quad-h \int_{t+T}^{\infty}\left[C_{2}(P *(t), \tau)-\frac{\partial C_{2}(P *(t), \tau)}{\partial P(t)} \frac{P *(t)}{\beta_{1}}\right] d \tau-k=0 .
\end{aligned}
$$


Equation (11) can be used to examine the stimulus effect of tax incentives. Implicitly differentiating equation (11) with respect to $T$ yields the following results: A longer tax holiday will discourage investment if

$$
h C_{2}\left(P^{*}(t), T\right)<h C_{2}(P *(t), T) \frac{\varepsilon(T)}{\beta_{1}},
$$

where $\varepsilon(\tau)=\dot{\tau} \ln C\left(P^{*}(t), \tau\right) / \tau^{2} \ln P(t)$ is the elasticity of the call option $C\left(P^{*}(t), \tau\right)$ with respect to $P(t)$ evaluated at $P(t)=P^{*}(t)$. A longer tax holiday results in the deference of tax bills, thus raising the value of investing immediately, as shown by the term on the left-hand side of equation (12). On the other hand, a longer tax holiday also makes a firm more flexibly wait and learn more about demand conditions while still being able to invest and earn profits before tax holidays expire, thus raising the option value from delaying investment; this effect is shown by the term on the right-hand side of equation (12). A longer tax holiday will discourage investment if the option value from delaying investment is raised by more than the value of investing immediately, as suggested by Result 1 .

Result 1. An increase in the duration of tax holiday, $T$, may paradoxically discourage investment by raising the critical level of output prices that triggers investment, $P^{*}(t)$.

I relate equation (12) to both the risk of the investment project $(\sigma)$ and the economic depreciation rate $\left(\delta_{1}\right)$ to gain more insight about Result 1. First, equation (12) will not hold under perfect foresight $(\sigma=0)$ but will be more likely to hold if $\sigma$ is very high; with perfect foresight, equation (12) would never be satisfied because $\Omega_{1}$ will then approach infinity, but $m(T)$ will remain finite. This accords to intuition: Under perfect foresight, as the tax holiday lasts longer, then a firm's value of investing immediately will be raised by more than will be its value from delaying investment. In contrast, the condition in equation (12) may hold when uncertainty interacts with tax holidays. This is because a firm's future payoff, which is truncated below at zero, is analogous to a financial call option so that the value of this payoff is increasing with risk. As a result, as the tax holiday lasts longer, the firm's 
value from delaying investment is possibly raised by more than its value of investing immediately if the investment project is very risky. Second, without accelerated depreciation allowances (i.e., $\delta_{1}=\delta_{2}$ ), equation (12) will then be more likely to hold if capital depreciates faster. This accords to intuition: A firm has more flexibility to delay investment under a longer tax holiday, and this increasing flexibility should be more important for a firm with short-lived than a firm with long-lived assets.

Implicitly differentiating equation (11) with respect to $h$ yields the following results: A higher corporate income tax rate will encourage investment if

$$
-\int_{t+T}^{\infty} C_{2}\left(P^{*}(t), \tau\right) d \tau>-\int_{t+T}^{\infty} C_{2}(P *(t), \tau) \frac{\varepsilon(\tau)}{\beta_{1}} d \tau .
$$

A higher tax rate reduces a firm's value of investing immediately because the firm needs to pay more taxes after tax holidays expire, as suggested by the term on the left-hand side of equation (13). On the other hand, a higher tax rate also reduces a firm's value from delaying investment, as suggested by the term on the right-hand side of equation (13); this is both because a firm's future flow profit is increasing with its risk and because a higher share of risky assets is taken by the government. A higher corporate tax rate will encourage investment if the firm's value of investing immediately is reduced by less than its option value from delaying investment. This idea is captured by Result 2, which is similar to that in MacKie-Mason (1990).

Result 2. An increase in the corporate income tax rate, $h$, may paradoxically encourage investment by reducing the critical level of output prices that triggers investment.

Both equations (12) and (13) are closely related to each other; equation (12) indicates that a longer tax holiday will discourage investment if the elasticity with respect to $P(t)$ of the call option expired at date $t+$ $T$ is greater than $\beta_{1}$. In contrast, equation (13) shows that a higher tax rate will encourage investment if the elasticities with respect to $P(t)$ of all the call options with maturity dates longer than $t+T$ are greater than $\beta_{1}$. Equations (12) and (13) do not imply each other. However, 
when equation (12) holds, equation (13) is also likely to hold, thus implying the following two results: First, if capital assets are short-lived, then a higher corporate tax rate will be more likely to encourage investment. This is because a higher corporate tax rate after the tax holiday expires should encourage a firm to make short-lived investments immediately and earn the resulting profits during the holiday, when they are untaxed. In contrast, a firm might be discouraged to make long-lived investments because much of the profits will occur after the holiday expires and will therefore be taxed at a higher rate. Second, if the investment project yields a return that is very volatile, a higher corporate tax rate will be more likely to encourage investment. This is because a firm's future payoff is more valuable if its investment project is more risky. When the firm undertakes a more risky project immediately, then the firm will be able to earn the resulting profits during the holiday, thus compensating its lower share of risky assets after the holiday expires.

\section{NUMERICAL ANALYSIS}

I demonstrate the results in the last section by numerical examples. Operating costs can be viewed as labor costs, whereas the sum of interest and maintenance costs can be viewed as capital costs. Consequently, it is plausible to impose $w:\left(r+\delta_{1}\right) k=2: 1$. I incorporate this requirement and choose a set of benchmark parameters, with parameter values $r=5 \%$ per year, $\delta_{0}=5 \%$ per year, $\bullet=20 \%$ per year, $\delta_{1}=\delta_{2}=5 \%$ per year, $h=0.25, k=10, w=2$, and $T=5 .{ }^{6}$ For this benchmark case, $P^{*}(t)=4.88$. For comparison, note that if all parameters are held at their benchmark values except that $h$ is replaced by zero, then $P^{*}(t)=$ 4.50, which is 1.5 times the Marshallian full cost, that is, $w+\left(r+\delta_{1}\right) k=$ 3.0. This indicates that due to the interaction of uncertainty and irreversibility, a firm will not invest until the rate of return is $50 \%$ above its normal rate.

Figure 1 depicts the effects of changes in the duration of tax holidays $(T)$ up to 20 years on the critical level of output prices that triggers investment $\left(P^{*}(t)\right)$, when either $\sigma$ or $\delta_{1}=\delta_{2}$ changes around its benchmark parameter values, whereas the other parameters are held at 


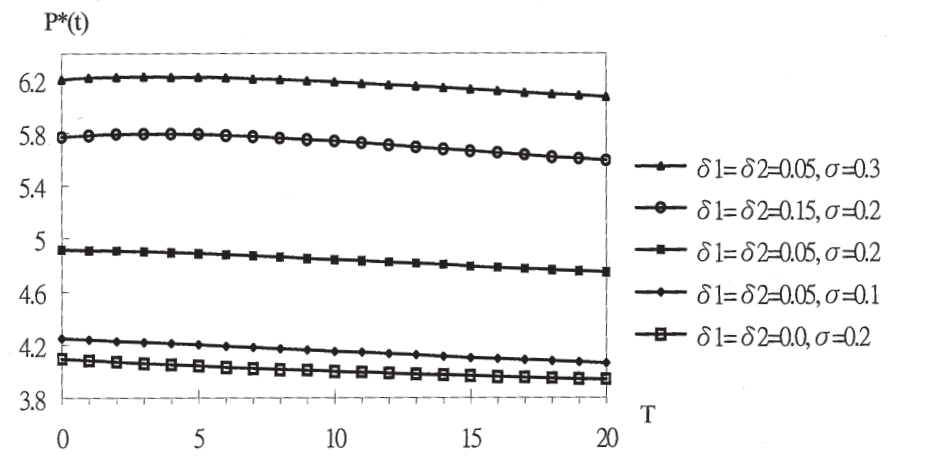

Figure 1: $P^{*}(t)$ Versus $T$

their benchmark values. Figure 1 shows that investment will be discouraged $\left(P^{*}(t)\right.$ is higher $)$ as capital assets either are short-lived $\left(\delta_{1}=\right.$ $\delta_{2}$ is higher) or yield a return that is more volatile ( $\sigma$ is higher); in the former case, the option value from delaying investment is reduced by less than is the value from investing immediately. In the latter case, the option value from delaying investment is increased by more than the value of investing immediately. Furthermore, when the tax holiday lasts less than 3 years, a longer tax holiday ( $T$ is higher) may discourage investment, which accords to Result 1 . This happens when either capital is depreciating at $15 \%$ per year or the volatility of the growth rate of output prices is $30 \%$ per year; this indicates that if either capital assets are short-lived or demand is very volatile, a longer tax holiday not only results in more tax revenue losses but also fails to stimulate investment.

Figure 2 depicts the effects of changes in corporate tax rates from $0 \%$ to $50 \%$ on the critical level of output prices that triggers investment when either $\sigma$ or $\delta_{1}=\delta_{2}$ changes, whereas the other parameters are held at their benchmark values. The paradox finding in Result 2, which states that a higher corporate tax rate may encourage investment, does not occur in Figure 2; this suggests that for capital assets that either are short-lived or yield a return that is very volatile, a higher corporate tax rate still discourages investment because the value of in- 


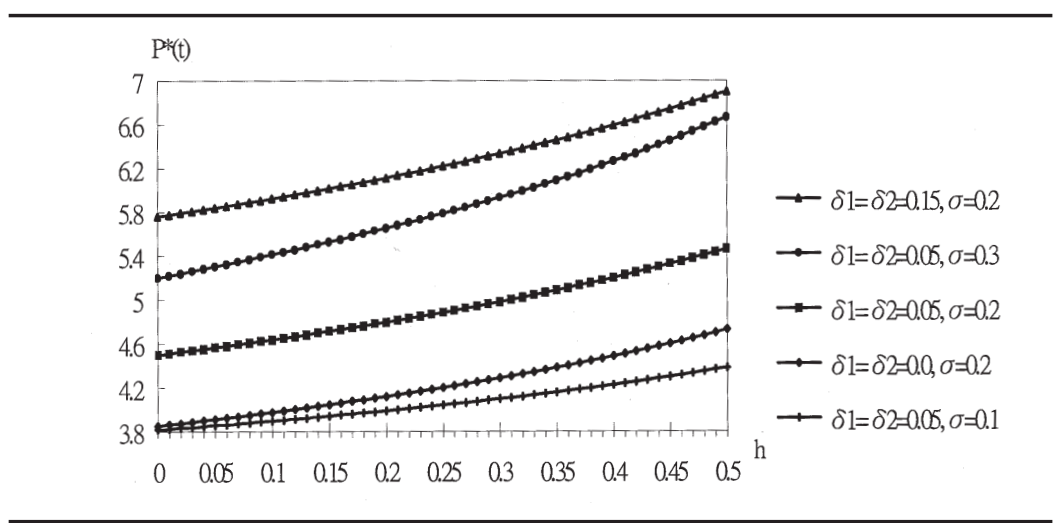

Figure 2: $P^{\star}(t)$ Versus $h$

vesting immediately is still reduced by more than is the option value from delaying investment.

\section{CONCLUDING REMARKS}

This article adopts the real options approach to examine the effect of a tax holiday on a firm's incentive to invest. The main finding is appealing: A more generous tax incentive, either a longer tax holiday or a lower corporate tax rate, not only results in more tax revenue losses but may also fail to stimulate investment. This is more likely to happen if capital assets either are short-lived or yield a return that is very volatile.

The model in this article can be extended in several ways. First, one can capture supply uncertainty by either allowing the variable cost $w$ or the investment cost $k$ to be stochastic (e.g., Dixit and Pindyck 1994, chap. 6). Second, one can assume that the investment costs are partially rather than fully sunk such that a firm can disinvest as well as invest (Dixit 1989). Finally, one can incorporate the taxation on direct foreign investment (e.g., Mintz and Tsiopoulos 1994). These extensions deserve attention but should not significantly affect the main finding of this article. 


\section{APPENDIX}

I follow Pindyck (1988, appendix) to derive both the firm's pretax investment value, $V_{1}(P(t))$ in equation (6), and its option value to invest, $F(P(t))$ in equation (7). Suppose that a project produces one unit of output per period with a stochastic price $P(t)$ while incurring the cost $w+\delta_{1} k$. The project can be temporarily shut down if $P(t)$ falls below $w+\delta_{1} k$. To value this project, let us create a portfolio $\Phi(t)$ that is long the project and short $\partial V_{1}(P(t)) / \hat{s}(P(t)$ units of the output or, equivalently, the asset or portfolio of assets perfectly correlated with $P(t)$. Because the expected growth rate of $P(t)$ is only $\mu_{P}$, the short position requires a payment $\delta_{0} P(t)\left(\partial V_{1}(\mathrm{t}) / \mathrm{s}(\mathrm{t}(\mathrm{P}(t))\right.$ per unit of time. The value of this portfolio is

$$
\Phi(t)=V_{1}(t)-\frac{\partial V_{1}(t)}{\partial P(t)} P(t)
$$

and its instantaneous return is

$$
d V_{1}(t)-\frac{\partial V_{1}(t)}{\partial P(t)} d P(t)-\delta_{0} P(t) \frac{\partial V_{1}(t)}{\partial P(t)} d t+j \cdot\left[P(t)-w-\delta_{1} k\right]
$$

The last term in equation (A2) is the cash flow from the project; $j$ is a switching variable: $j=1$ if $P(t) \geq w+\delta_{1} k$, and $j=0$ otherwise.

According to Itô's lemma,

$$
d V_{1}(t)=\frac{\partial V_{1}(t)}{\partial P(t)} d P(t)+\frac{1}{2} \frac{\partial^{2} V_{1}(t)}{\partial P^{2}(t)}(d P(t))^{2} .
$$

We can substitute equation (1) for $d P(t)$ as well as $(\mathrm{d} P(t))^{2}=\sigma_{2} P(t)^{2} d t$ into equation (A3). Because the return in equation (A1) is risk-less, we can equate

$$
r \Phi(t) d t=\left[r V_{1}(t)-r \frac{\partial V_{1}(t)}{\partial P(t)} P(t)\right] d t
$$

to the instantaneous return in equation (A2), thus yielding the differential equation

$$
\begin{aligned}
\frac{1}{2} \sigma^{2} P(t)^{2} \frac{\partial^{2} V_{1}(t)}{\partial P(t)^{2}} & +\left(r-\delta_{0}\right) P(t) \frac{\partial V_{1}(t)}{\partial P(t)} \\
& +j \cdot\left[P(t)-w-\delta_{1} k\right]-r V_{1}(t)=0 .
\end{aligned}
$$


The solution for $V_{1}(P(t))$ in equation (A5) must be satisfied by the following boundary equation:

$$
\begin{gathered}
V_{1}(0)=0, \\
\left.V_{1}(P(t))\right|_{P(t) \rightarrow \infty}=\frac{P(t)}{\delta_{0}}-\frac{w+\delta_{1} k}{r}
\end{gathered}
$$

and

$$
\left.\frac{\partial V_{1}(P(t))}{\partial P(t)}\right|_{P(t) \rightarrow \infty}=\frac{1}{\delta_{0}}
$$

Furthermore, $V_{1}(P(t))$ must be continuously differentiable at the switch point $P(t)=$ $w+\delta_{1} k$.

The complementary and particular solutions from the homogeneous and nonhomogeneous parts in equation (A5) can be derived as follows. First, plugging $V_{1}(P(t))=$ $P(t)^{\beta}$ into the homogeneous part in equation (A5) yields

$$
\frac{\sigma^{2}}{2} \beta(\beta-1)+\left(r-\delta_{0}\right) \beta-r=0 .
$$

Suppose that the larger and smaller roots in equation (A9) are denoted by $\beta_{1}$ and $\beta_{2}$, respectively, where $\beta_{1}>1$ and $\beta_{2}<0$. Note that $\delta_{0}$ is required to be positive for $V_{1}(P(t))$ to be convergent. Second, the sum of the two terms on the right-hand side of equation (A7) is the particular solution for $V_{1}(P(t))$ when $P(t) \geq w+\delta_{1} k$. Pooling all above information yields $V_{1}(P(t))$ as that shown by equation (6).

Following similar procedures as above and noting that the dividend for a waiting firm is equal to zero yields the following differential equation that solves the firm's option value to invest, $F(P(t))$ :

$$
\frac{1}{2} \sigma^{2} P(t)^{2} \frac{\partial^{2} F(P(t))}{\partial P(t)^{2}}+\left(r-\delta_{0}\right) P(t) \frac{\partial F(P(t))}{\partial P(t)}-r F(P(t))=0 .
$$

$F(P(t))$ must be satisfied in the following boundary conditions:

$$
F(0)=0
$$

thus yielding $F(P(t))$, as that shown by equation (7). 


\section{NOTES}

1. Some studies focus on how an optimal tax holiday policy is formed rather than the stimulus effect of a tax holiday (e.g., Doyle and van Wijnebergen 1984; Wen 1992).

2. This differs from Mintz (1990) and Mintz and Tsiopoulos (1994), both who emphasize the importance of the timing of depreciation allowances in determining the effective rates and the cost of capital to firms that consider additional investment during the tax holiday.

3. Depreciation allowances may be in many forms, including declining balances, straightline depreciation, and accelerated depreciation (Mintz 1990). My assumption here is for obtaining tractable solutions.

4. This contrasts with Stiglitz (1969), in which the taxable income with full-loss offsets will never be equal to that without full-loss offsets.

5. If the firm's output price cannot be spanned by existing assets, then the dynamic programming analysis should be used to derive the formula (Pindyck 1988, appendix).

6 . Both a tax holiday around 5 years and a corporate income tax rate around $25 \%$ are commonly adopted by many developing countries. Furthermore, the volatility of the growth rate of the output price being around $20 \%$ is also common for many industries (Pindyck 1988, n.14).

\section{REFERENCES}

Auerbach, A. J. 1986. The dynamic effects of tax law asymmetries. Review of Economic Studies 53:205-26.

Brennan, M. J., and E. S. Schwartz. 1985. Evaluating natural resource investment. Journal of Business 58:135-57.

Dixit, A. 1989. Entry and exit decision under uncertainty. Journal of Political Economy 97:62038.

Dixit, A., and R. S. Pindyck. 1994. Investment under uncertainty. Princeton, NJ: Princeton University Press.

Domar, E., and R. Musgrave. 1944. Proportional income taxation and risk taxation. Quarterly Journal of Economics 58:382-422.

Doyle, C., and S. van Wijnebergen. 1984. Taxation of foreign multinationals: A sequential bargaining approach to tax holidays. Center for Economic Policy Research Discussion Papers No. 25. Warwick, UK: University of Warwick.

Gordon, R. H. 1985. Taxation of corporate capital income: Tax revenues versus tax distortions. Quarterly Journal of Economics 100:1-27.

Harrison, J. M., T. M. Sellke, and A. J. Taylor. 1983. Impulsive control of Brownian motion. Mathematics of Operations Research 8:454-66.

Hassett, K. A., and G. E. Metcalf. 1992. Energy tax credits and residential conservation investment. NBER Working Paper No. 4020, Cambridge, MA.

MacKie-Mason, J. K. 1990. Some nonlinear tax effects on asset values and investment decision under uncertainty. Journal of Public Economic 42:301-28.

Majd, S., and S. C. Myers. 1985. Valuing the government's tax claim on risky assets. NBER Working Paper No. 1553, Cambridge, MA.

. 1986. Tax asymmetries and corporate income tax reform. NBER Working Paper No. 1924, Cambridge, MA. 
Mayer, C. 1986. Corporation finance, tax, and the cost of capital. Review of Economic Studies 53:93-112.

McDonald, R., and D. R. Siegel. 1984. Option pricing when the underlying asset earns a belownormal equilibrium rate of return. Journal of Finance 39:261-66.

- 1985. Investment and the valuation of firms when there is as option to shut down. International Economic Review 26:331-49.

Merton, R. 1973. The theory of rational option pricing. Bell Journal of Economics and Management Science 4:141-83.

Mintz, J. M. 1981. Some additional results on investment, risk taking, and full loss offset corporate taxation with interest deductibility. Quarterly Journal of Economics 96:631-42.

. 1990. Corporate tax holidays and investment. World Bank Economic Review 4 (1): 81102.

Mintz, J. M., and T. Tsiopoulos. 1994. The effectiveness of corporate tax incentives for foreign investment of tax crediting. Journal of Public Economics 55 (2): 233-55.

Pindyck, R. 1988. Irreversible investment, capacity choice, and the value of the firm. American Economic Review 79:969-85.

Stiglitz, J. 1969. Effects of wealth, income and capital gains taxation on risk taking. Quarterly Journal of Economics 83:263-83.

Wen, J. F. 1992. Tax holidays in a business climate. Queen's Institute for Economic Research, Discussion Paper No. 864.

Jyh-bang Jou is an associate professor of economics at the Graduate Institute of Three People's Principle, National Taiwan University, ROC. His research interests are applying real options to public finance theory and corporate finance theory. 